\title{
Editorial
}

\section{EI dilema de la Reforma Tributaria: ¿estructural o fiscalista?}

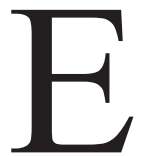

120 de octubre, el ministro de Hacienda, Mauricio Cárdenas, presentó ante el Congreso el proyecto de Ley de Reforma Tributaria, cuyo fundamento, en buena parte, es el informe de la Comisión de Expertos Tributaristas. El Gobierno nacional aspira a recaudar $\$ 7.2$ billones y, de esta forma, compensar la reducción de los ingresos de la nación provocados por factores tales como la caída de los precios del petróleo, la reducción del crecimiento económico, que -de acuerdo con proyecciones para 2016 del Banco de la República, puede ser de alrededor del $2 \%-$, y la eliminación de impuestos temporales a partir del 2018.

De hecho, la reforma a la estructura tributaria vigente abarca una gran variedad de gravámenes, midiéndose su relevancia según sea su impacto en el fisco nacional. Sin duda, los aportes más significativos provienen del impuesto a la renta y el impuesto al valor agregado (IVA), cada uno de ellos aporta, aproximadamente, el $40 \%$.

Según el ministro de Hacienda, la reforma pretende que los que ganen más, paguen más, así mismo, facilitar el cumplimiento de las obligaciones tributarias. Él argumenta que las sociedades que actualmente pagan cuatro impuestos directos (renta, contribución sobre la renta empresarial para la equidad (CREE), sobretasa al CREE y riqueza), pagarán solo uno: el de renta. Lo novedoso de la propuesta, en cuanto a los tributos directos, es el impuesto a los dividendos. Esta iniciativa se presentó en la legislatura de 2014; empero, en esa ocasión, no se adoptó porque los congresistas argumentaron que de hacerlo se generaría una doble tributación. En la actualidad existe un clima favorable para implementarlo, ya que a nivel mundial la propuesta de equidad tributaria de Piketty ha tenido una gran aceptación. El economista francés argumenta que para combatir la desigualdad, teniendo en cuenta que la tasa de crecimiento de la economía es menor que la tasa de rendimiento del capital, es necesario gravar directamente el capital; por ello, en la iniciativa legislativa las personas naturales de mayores ingresos deben contribuir más al fisco.

Alrededor de los impuestos directos han surgido opiniones divergentes. Para el presidente de la Asociación Nacional de Industriales (ANDI), Bruce Mac Master, la propuesta no contribuye a mejorar la competitividad de las empresas, ya que si se comparan los cuatro tributos arriba descritos con los dos incluidos en el proyecto de reforma (renta y dividendos), resulta que la suma de estos dos últimos es mayor que lo que pagan actualmente los empresarios. Según el dirigente gremial, para el 2017, con la combinación existente frente al nivel establecido en el proyecto de reforma, pasaría del 42,1 al 44,8\%, es decir, la tarifa se incrementaría. En el 2018 se mantendría en el 42,1\% y, a partir del 2019, según la composición actual del impuesto de renta, se situaría en el $34 \%$. Además, con lo sugerido en la propuesta, este ascendería al 
$39 \%$. En suma, para la ANDI, el monto de los impuestos directos sugeridos en el proyecto de reforma es más alto que el que se paga actualmente, lo cual, si se aprueba como está, afectará la inversión y, por ende, el crecimiento económico y la generación de empleo.

Por otro lado, para algunos analistas como Eduardo Sarmiento, Jorge Iván González y Armando Rodríguez, entre otros, la propuesta de reforma tributaria en lo pertinente a los impuestos directos no es progresiva. Sarmiento considera que al sustituir el impuesto a la riqueza y al ingreso por el de renta y los dividendos, se reduce la contribución efectiva de un 41 a un $33 \%$, esto es, se sustituyen los gravámenes directos por los indirectos, y se reduce la progresividad del patrimonio y del ingreso a las personas jurídicas, aumentando la tributación del trabajo en comparación con la del capital.

Por su parte, González precisa que la tarifa del impuesto a la renta declina en cuanto el ingreso sube, "en lugar de volverse exponencial". Al no afectar sustancialmente la propiedad y la riqueza, la reforma no es progresiva y, por consiguiente, no contribuye a la equidad. Rodríguez sostiene que para el 2014 la tarifa efectiva tanto para el agregado de renta como para el IVA, fue de 21,7 y $21,3 \%$, respectivamente, lo cual desvirtúa la tesis de quienes consideran que las empresas aportan al Estado el $70 \%$ de sus ganancias.

En torno al principal impuesto indirecto, el IVA, la propuesta contempla la posibilidad de subir la tarifa general del 16 al $19 \%$. Algunos productos, como azúcar, pastas, café, entre otros que vienen pagando un IVA del $5 \%$, mantienen dicha tarifa. El grueso de la canasta familiar queda exento del mencionado tributo. Sin duda, este es el punto más controversial del proyecto de reforma tributaria y el que más críticas ha suscitado, debido a que el IVA es un impuesto regresivo, ya que lo pagan todas las personas, independientemente de que tengan un ingreso alto o bajo.

De lo anterior se puede inferir que la propuesta de reforma tributaria no es estructural, sino más bien fiscalista. Para que sea estructural, afirma González, se necesita que cumpla dos condiciones: en primer lugar, deben tenerse en cuenta tanto los impuestos como los subsidios y el efecto neto de los mismos en los hogares. Si bien en el proyecto se menciona la necesidad de evaluar la repercusión que tendrían en los hogares los dos instrumentos, no se profundiza en los impactos que estos tendrían en comparación con los subsidios existentes.

En segundo lugar, es crucial, si la reforma altera de forma sustancial las relaciones entre los factores de producción (capital y trabajo). En la propuesta se cuestiona la tarifa nominal del impuesto sobre la renta de las empresas, aduciendo que es muy alta en comparación con países de similar desarrollo al nuestro, pero no precisa la magnitud de la tarifa efectiva que es determinante, siendo considerablemente inferior. A pesar de ello, en la propuesta son los hogares de clase media baja (salarios a partir de \$2.300.000 mensuales) los que ahora tendrán que pagar impuesto sobre la renta. La reforma es fiscalista en la medida en que servirá para taponar el déficit fiscal actual, así como para resolver algunos problemas de los contribuyentes y eliminar algunas limitaciones del régimen tributario vigente.

LUIS E. VALLEJO ZAMUDIO

Director de la Revista Apuntes del Cenes 